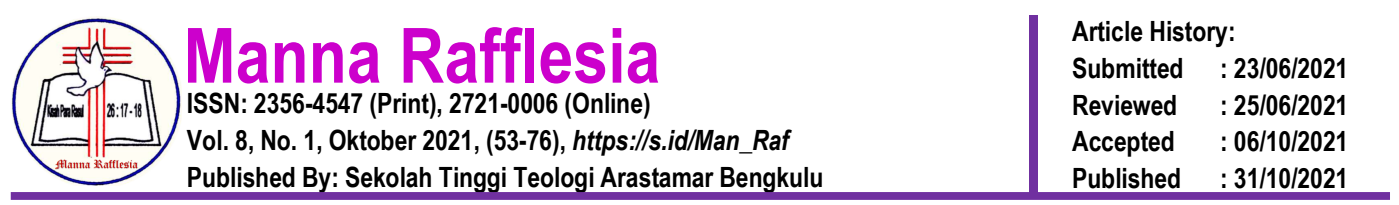

\title{
KORELASI POSITIF MENGUMPULKAN HARTA DI SURGA DENGAN KERAJAAN ALLAH DI KALANGAN GEMBALA GEREJA SUARA KEBENARAN INJIL
}

\author{
Timotius Tan $^{1 *}{ }^{*}$, Erastus Sabdono ${ }^{2}$, Muner Daliman ${ }^{3}$, Timotius Sukarna ${ }^{4}$ \\ Sekolah Tinggi Teologi Ekumene Jakarta ${ }^{12}$, Sekolah Tinggi Teologi Kadesi \\ Yogyakarta ${ }^{3}$, Sekolah Tinggi Teologi Kadesi Bogor ${ }^{4}$ \\ *)Email Correspondance: timotiustan72@gmail.com
}

\begin{abstract}
Many people are facing problems with money, including Christian Leaders. Problems appear when a pastor serves otthers in order to gain prosperity. This attitude caused his teachings by emphasizing a successful life. Wealthy tend to be a standard of success. Surely the prosperity Gospel is false because Jesus Christ taught His believers to gain spiritual wealth in Heaven by giving priority to the kingdom of God (Matthew 6:19-34). This lack of attitude occurred among the pastors of the Synod of the Bible's Truthful Voice Church (abbreviated as GSKI). Therefore, this article aims to seek the correlation between the GSKI pastors' perception of the concept of gaining treasure in Heaven consider to the Kingdom of God. Using the Quantitative Method, Correlational type, the Hypothesis is testing with SPSS 20 application. The results showed that the attitude of seeking treasure in heaven is a pattern of life that is formed by the pastor motive who give priority to serving God, the kingdom of God and His righteousness simultaneously. Hence, this article contributes to the research on how to practice the Kingdom values.
\end{abstract}

Keywords: $\quad$ Kingdom of God, Prosperity, Priority.

Abstraksi: $\quad$ Banyak orang memiliki masalah dengan uang, termasuk pendeta. Masalah timbul ketika motivasi melayani untuk mengejar materi. Ajarannnya pun cenderung menekankan kehidupan sukses atau diberkati. Kekayaan menjadi ukuran keberhasilan. Tentu hal ini keliru karena Yesus Kristus mengajarkan pengikut-Nya mengumpulkan harta di Surga dengan memprioritaskan kerajaan Allah (Mat. 6: 19-34). Kondisi di atas juga terjadi di kalangan para gembala sidang Sinode Gereja Suara Kebenaran Injil (GSKI). Penelitian ini bertujuan untuk mengetahui korelasi antara pemahaman para gembala sidang GSKI akan konsep mengumpulkan harta di Surga dengan memprioritaskan Kerajaan Allah. Metode yang dipakai adalah Metode Kuantitaf, jenis Korelational. Pengujian hipotesis dengan Program SPSS 20. Hasil penelitian menunjukkan bahwa sikap mengumpulkan harta di surga merupakan sebuah pola hidup keseharian yang terbentuk dari motivasi seorang hamba Tuhan yang terdiri dari tiga prinsip utama yaitu: memprioritaskan pengabdian pelayanan hanya kepada Allah, kerajaan Allah dan kebenaran-Nya secara simultan. Tulisan ini menjadi sumbangsih bagi penelitian tentang implementasi nilai-nilai Kerajaan Allah.

Kata Kunci: $\quad$ Kerajaan Allah, Harta, Prioritas.

\section{PENDAHULUAN}


Kehidupan sukses sering diidentifikasi dengan banyak harta benda. Pandangan dunia tentang harta memang berbeda dengan pandangan Alkitab. Pandangan dunia mengajarkan untuk mengumpulkan harta di bumi bagi kepentingan dan kesenangan diri sendiri serta menjadi ukuran kesuksesan. Sedangkan Alkitab mengajarkan untuk mengumpulkan harta di surga bagi kepentingan dan kemuliaan Allah (Mat. 6: 19-34). Tidak ada salahnya manusia memiliki kekayaan, yang salah adalah apabila kekayaan menguasai manusia. Alkitab mengajarkan bahwa akar segala kejahatan ialah cinta uang (1Tim. 6: 10). Herlianto dalam buku "Teologi Sukses" mengungkapkan paling tidak ada empat hal utama yang diprioritaskan manusia dalam hidupnya di bumi untuk meraih sukses yaitu: kekayaan, popularitas, kekuasaan dan prestasi. ${ }^{1}$ Keempat hal tersebut menjadi ajaran utama dari Teologi Sukses yang muncul di Amerika pada abad ke-20 dan masuk ke Asia, pertama di Korea Selatan dan akhirnya sampai ke Indonesia.

Teologi Sukses atau disebut juga Teologi Kemakmuran, teologi ini mengajarkan bahwa ukuran kesuksesan kehidupan pengikut Kristus ialah kekayaan dan kesehatan. Hal ini sekaligus menjadi bukti kehidupan yang berkenan kepada Allah. Smith menjelaskan bahwa Teologi Sukses (Prosperity Theology) dipelopori oleh Robert Schuller, murid dari Norman Vincent Pearl yang mengajarkan Positive Thingking, keduanya sama yaitu mengabungkan agama dan psikologi. Teologi Kemakmuran mulai berkembang di Amerika tahun 1960-an dan banyak penginjil kemudian mengajarkan teologi ini. ${ }^{2}$ Demikian juga ada para gembala sidang yang tergabung dalam sinode Gereja Suara Kebenaran

1 Herlianto, Teologi Sukses (Jakarta: BPK Gunung Mulia, 2012), 152.

2 David L. Smith, A Handbook of Contemporary Theology: Tracing Trends and Discerning Directions in Today's Theological (Grand Rapids, Michigan: Baker Books, 2000), 179-181. 
Injil (GSKI) Indonesia, ada yang terpengaruh dengan ajaran teologi sukses. Ada hamba Tuhan yang memiliki motivasi bergabung ke sinode GSKI hanya ingin mendapat bantuan keuangan. Kondisi ini disebabkan oleh berbagai faktor kendala atau penyebab, di antaranya faktor ekonomi jemaat yang mengakibatkan ekonomi hamba Tuhan menurun dan tuntutan hidup, sehingga tanpa disadari banyak diantaranya sudah menganut ajaran teologi kemakmuran. ${ }^{3}$

Penelitian ini menekankan inti kebenaran tentang mengumpulkan harta di Surga berhubungan erat dengan penerapan konsep memprioritaskan Kerajaan Allah sebagai ukuran kesuksesan hidup orang Kristen seperti yang diajarkan Tuhan Yesus dalam Matius 6: 33 dan bukan berdasarkan teologi sukses. Pengikut Kristus sepatutnya memprioritaskan sukses menurut standar ajaran firman Tuhan, bukan menurut ukuran atau pandangan duniawi.

Sinode GSKI memiliki pemahaman teologis yang berbeda dengan teologi sukses soal ukuran kesuksesan. ${ }^{4}$ Sinode GSKI menganut teologi yang dikenal dengan Suara Kebenaran yang dipelopori oleh Pdt. Dr. Erastus Sabdono sebagai Pendiri atau Founder sinode GSKI. Sinode GSKI meyakini bahwa kesuksesan itu diukur sejauh mana orang percaya memprioritaskan Kerajaan Allah, artinya melakukan segala sesuatu yang menyenangkan hati Bapa melalui setiap kata yang diucapkan, pilihan, keputusan dan semua tindakan. ${ }^{5}$ Hal inilah yang menjadi standar atau ukuran kehidupan Kristen yang sukses menurut ajaran sinode GSKI, jadi ukurannya bukan materi, melainkan perwujudan nilai-nilai Kerajaan Allah

3 Judika Sihaloho, Wawancara dengan Penulis, 22 November 2019.

${ }^{4} \mathrm{Hal}$ ini kontras dari gereja-gereja aliran Pentakosta dan Karismatik, salah satu contohnya Sinode Gereja Bethany Indonesia (Lih. Cindy Quartyamina Koan dan Yahya Wijaya, "Teologi sukses dan spiritual capital :: Kajian terhadap teologi sukses Gereja Bethany Indonesia-Surabaya dari perspektif spiritual capital dalam konteks Indonesia" (Universitas Gadjah Mada, 2008), http://etd.repository.ugm.ac.id/penelitian/detail/40228.)

5 Erastus Sabdono, Datanglah KerajaanMu (Jakarta: Rehobot Literature, 2019 ), 46. 
dalam kehidupan setiap orang percaya. Para pengerja di sinode GSKI dimotivasi untuk memahami prinsip ini dan menerapkannya dalam kehidupan dan pelayanan.

Oleh karena kesusksesn hidup orang Kristen berkaitan dengan kerajaan Allah maka patut dicermati terlebih dahulu beberapa penelitian sebelumnya yang terkait dengan penelitian ini yaitu tentang topik kerajaan Allah, misalnya dalam penelitian yang dilakukan oleh Panggara yang menjelaskan bahwa Kerajaan Allah yang diajarkan Yesus dalam Injil Matius sarat dengan nilai-nilai etis. ${ }^{6}$ Kajian lainnya tentang kerajaan Allah dilakukan oleh Ferry Yang, yang menjelaskan Kerajaan Allah dari sisi pengertian teologis. ${ }^{7}$ Selanjutnya ada penelitian yang berupaya membahas sisi praktis dari kerajaan Allah, seperti penelitian Wisantoro yang mengorelasikan kerajaan Allah dengan pemuridan ${ }^{8}$ juga penelitian Wijaya dan Harimisa mengkaji spiritualitas yang mengutamakan kasih sebagai inti kerajaan Allah yang teraplikasi dalam kehidupan orang Kristen. ${ }^{9}$ Fokus penelitian ini hendak membahas upaya memprioritaskan Kerajaan Allah itu baik dalam tataran pemahaman teologis dan praktis sekaligus. Dengan demikian, artikel ini ditulis dengan tujuan untuk memperkaya penelitian yang menyangkut Kerajaan Allah dan implementasinya sebagai standar kehidupan Kristen yang sukses dan sejati. Dengan mengambil populasi penelitian dari kalangan para hamba Tuhan yang berasal dari sinode GSKI Indonesia yang berpusat di Jakarta. Hasil

${ }^{6}$ Robby Panggara, "Konsep Kerajaan Allah Menurut Injil-Injil Sinoptik," Jurnal Jaffray, 1, 1 (2013), http://dx.doi.org/10.25278/jj71.v11i1.74.

7 Ferry Yang, "Kerajaan Allah: Sebuah Tinjauan Eksegesis," Jurnal Veritas, 1, 15 (2014): 35-59, http://repository.seabs.ac.id/handle/123456789/296.

8 Sandra Wisantoso, "Korelasi Konsep Kerajaan Allah Dan Pemuridan Dalam Injil Matius Bagi Pemuridan Masa Kini," Veritas: Jurnal Teologi Dan Pelayanan 18, no. 1 (15 Oktober 2019): 45-67, https://doi.org/10.36421/veritas.v18i1.323.

9 Hengki Wijaya dan Yoktafianus Harimisa, "Spiritualitas Kerajaan Allah: Khotbah Yesus di Bukit dan Implikasinya bagi Kehidupan Kristen," 20 Desember 2015, https://repository.sttjaffray.ac.id/id/publications/269449/. 
penelitian ini juga menjadi sumbangsih berupa input atau masukan dan evaluasi bagi para hamba Tuhan di sinode GSKI.

\section{METODE}

Metode penelitian yang digunakan dalam penelitian ini adalah metode kuantitatif jenis korelational untuk menjelaskan korelasi antar variabel penelitian. ${ }^{10}$ Korelasi yang dimaksud disini adalah korelasi positif antara variabel $\mathrm{X}$ dan Y. Penggunaan metode ini bertujuan untuk mengetahui angka dari hubungan pemahaman gembala jemaat GSKI seluruh Indonesia tentang prinsip mengumpulkan harta di surga (Variabel X) dengan Kerajaan Allah berdasarkan Matius 6: 19-34 (Variabel Y). Sampel penelitian diambil dari jumlah para Gembala Sidang yang tergabung dalam Sinode GSKI di seluruh Indonesia sebanyak 140 orang. Sampel uji coba sebanyak 30 orang, sehingga total hanya 110 orang yang menjadi responden yang mengisi instrumen penelitian. Selanjutnya, dilakukan analisis dan penghitungan data menggunakan sebuah aplikasi yaitu Program Statistical Product and Service Solutions (SPSS) versi 20. Variabel yang diteliti terdiri dari Variabel $\mathrm{X}=$ Mengumpulkan Harta di Surga; Varibael $\mathrm{Y}=$ Kerajaan Allah, yang terbagi ke dalam Variabel $\mathrm{Y} 1=$ Memprioritaskan Pengabdian Hanya Kepada Allah; Variabel Y2 = Memprioritaskan Kerajaan Allah; Variabel Y3 = Memprioritaskan Kebenaran Kerajaan Allah.

HASIL

10 Sasmoko Sasmoko, Metode Penelitian (Jakarta: UKI Press, 2003), 114. 
Hipotesis yang dipakai dalam penelitian ini adalah Hipotesis Asosiatif yaitu mencari hubungan atau korelasi antara dua variabel atau lebih. Hipotesis penelitian yang diuji adalah: Pertama, R1 yaitu "ada korelasi yang kuat antara mengumpulkan harta di Surga dengan memprioritaskan pengabdian hanya kepada Allah (Y1), kerajaan Allah (Y2) dan kebenaran kerajaan Allah (Y3) secara bersama-sama". Kedua, R2 yaitu "ada korelasi yang kuat antara mengumpulkan harta di Surga dengan memprioritaskan pengabdian hanya kepada Allah (Y1)". Ketiga, R3 yaitu "ada korelasi yang kuat antara mengumpulkan harta di Surga dengan memprioritaskan kerajaan Allah (Y2)". Kempat, R4 yaitu "ada korelasi yang kuat antara mengumpulkan harta di Surga dengan memprioritaskan kebenaran kerajaan Allah (Y3)". Kelima, R5 yaitu "variabel yang paling dominan memiliki korelasi mengumpulkan harta di Surga adalah variabel memprioritaskan kebenaran kerajaan Allah (Y3)".

\section{Uji Persyaratan Analitis}

Sebelum dilakukan pengujian hipotesis, maka sesuai prosedur analisis data akan dilakukan terlebih dahulu 'uji persyaratan analitis' terhadap sampel dalam populasi penelitian yang terdiri dari 'uji normalitas', 'uji linieritas' dan 'uji homogenitas'. Uji normalitas dilakukan untuk mengetahui apakah populasi data terdistribusi secara normal. Uji linieritas untuk mengetahui bentuk hubungan yang terjadi antara variabel $\mathrm{X}$ dan $\mathrm{Y}$. Kemudian uji homogenitas untuk memperlihatkan apakah dua atau lebih kelompok data sampel berasal dari populasi memiliki variasi yang sama. ${ }^{11}$ Demikian prosedur pengujian keandalan instrumen dan analisis data yang akan ditempuh dalam penelitian ini.

11 Sasmoko, Metode Penelitian (Jakarta: Media Plus, 2011), 311. 


\section{Uji Normalitas}

Berdasarkan hasil hitung data yang dilakukan dengan program SPSS 20, maka data dikatakan terdistribusi normal jika angka setiap variabel memiliki taraf signifikan di atas 0,05 yang menandakan bahwa variabel tersebut terdistribusi dengan normal dan dapat diukur. Adapun hasil uji normalitas yang telah dihitung berdasarkan SPSS 20 adalah sebagai berikut:

Pertama, data variabel X "Mengumpulkan Harta di Surga" memiliki signifikan 0,108, atau lebih dari 0,05 maka berdistribusi normal dan dapat diukur. Kedua, data variabel Y "Kerajaan Allah" memiliki signifikan 0,065 atau lebih dari 0,05 maka berdistribusi normal dan dapat diukur. Ketiga, data variabel Y1 "Memprioritaskan pengabdian hanya kepada Allah" berdasarkan Matius 6: 19-34 memiliki signifikan 0,062 atau lebih dari 0,05 maka dinyatakan berdistribusi normal dan dapat diukur. Keempat, data variabel Y2 "Memprioritaskan Kerajaan Allah” berdasarkan Matius 6: 19-34 memiliki signifikan 0,083, atau lebih dari 0,05 maka dinyatakan berdistribusi normal dan dapat diukur. Kelima, data variabel Y3 "Memprioritaskan Kebenaran Kerajaan Allah" berdasarkan Matius 6: 19-34 memiliki signifikan 0,090 atau lebih dari 0,05 maka dinyatakan berdistribusi normal dan dapat diukur.

\section{Uji Linieritas}

Uji linieritas dilakukan untuk mengetahui bentuk hubungan atau korelasi yang terjadi antara variabel $\mathrm{X}$ dan $\mathrm{Y}$. Hasil uji linieritas sebagai berikut:

\begin{tabular}{|c|c|c|c|c|c|c|c|}
\hline & & & $\begin{array}{l}\text { Sum of } \\
\text { Squares }\end{array}$ & $\mathrm{Df}$ & $\begin{array}{l}\text { Mean } \\
\text { Square }\end{array}$ & $\mathrm{F}$ & Sig. \\
\hline Memprioritaskan & & (Combined) & 11356.731 & 18 & 630.930 & 9.022 & .000 \\
\hline $\begin{array}{c}\text { pengabdian } \\
\text { hanya kepada }\end{array}$ & Between & Linearity & 7059.881 & 1 & 7059.881 & 100.956 & .000 \\
\hline $\begin{array}{c}\text { Allah, Kerajaan } \\
\text { Allah dan } \\
\text { Kebenaran }\end{array}$ & Groups & $\begin{array}{l}\text { Deviation } \\
\text { from } \\
\text { Linearity }\end{array}$ & 4296.850 & 17 & 252.756 & 3.614 & .170 \\
\hline $\begin{array}{l}\text { Kerajaan Allah } \\
\text { berdasarkan } \\
\text { Matius 6:19-34 * }\end{array}$ & \multicolumn{2}{|c|}{ Within Groups } & 6363.632 & 91 & 69.930 & & \\
\hline $\begin{array}{l}\text { Mengumpulkan } \\
\text { Harta di Sorga }\end{array}$ & \multicolumn{2}{|c|}{ Total } & 17720.364 & 109 & & & \\
\hline
\end{tabular}


Tabel 1. ANOVA Uji Lineritas X-Y

Dari output pengujian linieritas Variabel $\mathrm{X}$ ke $\mathrm{Y}$ di atas menunjukkan bahwa nilai signifikansi liniearity adalah 0,000 dan deviation from linearity sebesar 0,170 lebih besar 0,05 maka dapat disimpulkan bahwa Variabel $\mathrm{X}$ dinyatakan linier dengan Variabel Y.

\section{Uji Homogenitas}

Uji homogenitas dimaksudkan untuk memperlihatkan bahwa dua atau lebih kelompok data sampel berasal dari populasi yang memiliki variansi (kuadrat simpangan baku) yang sama. Pada analisis regresi, persyaratan analisis yang dibutuhkan adalah bahwa kekeliruan atau galat regresi untuk setiap pengelompokan berdasarkan variabel terikatnya memiliki variansi yang sama.

\section{Memprioritaskan pengabdian hanya kepada Allah, Kerajaan Allah dan Kebenaran Kerajaan Allah berdasarkan Matius 6:19-34}

\begin{tabular}{|c|c|c|c|}
\hline $\begin{array}{c}\text { Levene } \\
\text { Statistic }\end{array}$ & df1 & df2 & Sig. \\
\hline 2.656 & 13 & 91 & .203 \\
\hline
\end{tabular}

Tabel 2. Uji Homogenitas Y-X

Dari hasil analisis data SPSS 20 untuk uji homogenitas antara variabel Y dengan variabel $\mathrm{X}$ maka dapat diketahui $p$-value $=0,203>0,05$ maka dapat disimpulkan data diambil dari sampel yang homogen atau sama.

\section{Pengujian Hipotesis}

Berdasarkan pengujian normalitas, linieritas dan homogenitas dapat disimpulkan data variabel independen (Variabel X) dan variabel dependen ( 
Variabel Y, Variabel Y1, Y2, Y3 ) adalah berdistribusi normal dan terdapat hubungan yang linier serta homogen dari setiap variabel. Dengan demikian, selanjutnya dapat dilakukan pengujian hipotesis asosiatif berdasarkan tabel Korelasi Pearson untuk membuktikan kuat atau lemahnya hubungan variabel $\mathrm{X}$ dan Y. Berikut dipaparkan tabel Korelasi Pearson sebagai acuan mengukur tingkat korelasi antara variabel $\mathrm{X}$ dan $\mathrm{Y}$ dalam table 3 di bawah ini:

\begin{tabular}{|c|c|}
\hline Interval Koefisien & Tingkat Hubungan \\
\hline $0,800-1,000$ & Berhubungan Sangat Kuat \\
$0,600-0,799$ & Berhubungan Kuat \\
$0,400-0,599$ & Berhubungan Cukup \\
$0,200-0,399$ & Berhubungan Rendah \\
$0,000-0,199$ & Berhubungan Sangat Rendah \\
\hline
\end{tabular}

Tabel 3. Korelasi Pearson

\section{Hasil Pengujian Hipotesis 1.}

\begin{tabular}{|c|c|c|c|c|}
\hline Model & $\mathrm{R}$ & $\mathrm{R}$ Square & $\begin{array}{c}\text { Adjusted R } \\
\text { Square }\end{array}$ & $\begin{array}{c}\text { Std. Error of the } \\
\text { Estimate }\end{array}$ \\
\hline 1 & $.631^{\mathrm{a}}$ & .398 & .393 & 9.93520 \\
\hline \multicolumn{3}{|c|}{ Tabel 4. Model Summary Variabel X-Y } \\
\hline
\end{tabular}

Tabel 4 di atas membuktikan bahwa ada hubungan yang positif antara mengumpulkan harta di sorga dengan memprioritaskan pengabdian hanya kepada Allah, Kerajaan Allah dan Kebenaran Kerajaan Allah (Variabel Y1, Y2, Y3) berdasarkan Matius 6: 19-34 di kalangan hamba Tuhan sinode GSKI di seluruh Indonesia, namun ditunjukkan dengan interval korelasi 0,389 atau rendah. Dengan demikian Hipotesis 1 (R1) yaitu "Ada Korelasi Yang Kuat Antara 
Mengumpulkan Harta di Surga Dengan Memprioritaskan Pengabdian Hanya Kepada Allah (Y1), Kerajaan Allah (Y2) dan Kebenaran Kerajaan Allah (Y3) secara bersama-sama”, ternyata ditolak atau tidak terbukti.

\section{Hasil Pengujian Hipotesis 2.}

\begin{tabular}{|c|c|c|c|c|}
\hline Model & $\mathrm{R}$ & $\mathrm{R}$ Square & $\begin{array}{c}\text { Adjusted R } \\
\text { Square }\end{array}$ & $\begin{array}{c}\text { Std. Error of the } \\
\text { Estimate }\end{array}$ \\
\hline 1 & $.653^{\mathrm{a}}$ & .426 & .420 & 4.28153 \\
\hline
\end{tabular}

Tabel 5. Model Summary Variabel X-Y1

Tabel di atas membuktikan bahwa varibel Y1 yaitu "Memprioritaskan Pengabdian Hanya Kepada Allah" di kalangan hamba Tuhan GSKI di seluruh Indonesia (Y1) memiliki korelasi atau hubungan yang cukup dengan rentang interval 0.426. Dengan demikian hipotesis Kedua (R2) yaitu "Ada Korelasi Yang Kuat Antara Mengumpulkan Harta di Surga Dengan Memprioritaskan Pengabdian Hanya Kepada Allah (Y1)" tidak terbukti atau ditolak.

\section{Hasil Pengujian Hipotesis 3.}

\begin{tabular}{|c|c|c|c|c|}
\hline Model & $\mathrm{R}$ & R Square & $\begin{array}{c}\text { Adjusted R } \\
\text { Square }\end{array}$ & $\begin{array}{c}\text { Std. Error of the } \\
\text { Estimate }\end{array}$ \\
\hline 1 & $.561^{\mathrm{a}}$ & .315 & .309 & 3.61666 \\
\hline
\end{tabular}

Tabel 6. Model Summary Variabel X-Y2

Tabel 6 di atas membuktikan bahwa prinsip "Memprioritaskan Kerajaan Allah" (Variabel Y2) berdasarkan Matius 6:19-34 di kalangan hamba Tuhan GSKI di seluruh Indonesia (Y2) memiliki korelasi atau hubungan yang rendah dengan rentang interval 0.315. Dengan demikian, hipotesis ketiga (R3) yaitu "Ada 
Korelasi Yang Kuat Antara Mengumpulkan Harta di Surga dengan Memprioritaskan Kerajaan Allah (Y2)" dinyatakan ditolak atau tidak terbukti.

\section{Hasil Pengujian Hipotesis 4}

\begin{tabular}{|c|c|c|c|c|}
\hline Model & $\mathrm{R}$ & $\mathrm{R}$ Square & $\begin{array}{c}\text { Adjusted R } \\
\text { Square }\end{array}$ & $\begin{array}{c}\text { Std. Error of } \\
\text { the Estimate }\end{array}$ \\
\hline 1 & $.513^{\mathrm{a}}$ & .263 & .256 & 3.25738 \\
\hline
\end{tabular}

Tabel 7. Model Summary Variabel X-Y3

Tabel 7 di atas membuktikan bahwa besarnya koefisien determinasi variansi (r2) sebesar 0,263 yang berarti hubungan "Mengumpulkan Harta di Surga" (X) dengan "Memprioritaskan Kebenaran Kerajaan Allah" (Y3) berdasarkan Matius 6: 19-34 di kalangan hamba Tuhan GSKI (Y3) hanya berada pada rentang interval rendah. Dengan demikian Hipotesis keempat (R4) yaitu "Ada Korelasi Yang Kuat Antara Mengumpulkan Harta di Surga dengan Memprioritaskan Kebenaran Kerajaan Allah (Y3)", dinyatakan ditolak atau tidak terbukti.

\section{Hasil Pengujian Hipotesis 5}

\begin{tabular}{|l|r|r|}
\hline Independent Variable & Importance & $\begin{array}{l}\text { Normalized } \\
\text { Importance }\end{array}$ \\
\hline $\begin{array}{l}\text { Memprioritaskan } \\
\text { Pengabdian Hanya Kepada } \\
\text { Allah (Y1) }\end{array}$ & 10.243 & $100.0 \%$ \\
\hline $\begin{array}{l}\text { Memprioritaskan Kerajaan } \\
\text { Allah (Y2) }\end{array}$ & 9.284 & $90.6 \%$ \\
\hline $\begin{array}{l}\text { Memprioritaskan Kebenaran } \\
\text { Kerajaan Allah (Y3) }\end{array}$ & 8.403 & $82.0 \%$ \\
\hline
\end{tabular}

Tabel 8. Independent Variable Importance 
Berdasarkan Tabel 8 di atas, menunjukkan bahwa varibel yang paling dominan memiliki korelasi dengan prinsip "Mengumpulkan Harta di Surga" (Variabel X) adalah Variabel Y1 yaitu "Memprioritaskan Pengabdian Hanya Kepada Allah", dengan besaran importasi sebesar 10,243 atau setara dengan 100\%. Dengan demikian, hipotesis kelima (R5) yaitu "Variabel yang paling dominan memiliki korelasi dengan mengumpulkan harta di Surga adalah variabel memprioritaskan kebenaran kerajaan Allah (Y3)" dinyatakan ditolak.

\section{PEMBAHASAN}

Bagian ini membahas hasil uji hipotesis penelitian yang diajukan yaitu berupa korelasi antara Variabel X yaitu: “"Mengumpulkan Harta di Sorga" dengan Variabel Y yaitu: "Kerajaan Allah" yang terdiri dari tiga bagian yaitu: "Memprioritaskan Pengabdian Hanya kepada Allah" (Y1), "Memprioritaskan Kerajaan Allah" (Y2), dan "Memprioritaskan Kebenaran Kerajaan Allah" (Y3), dan variabel yang dominan berkorelasi dengan variable $\mathrm{X}$ yaitu sebagai berikut:

\section{Korelasi Prinsip "Mengumpulkan Harta di Surga" (X) Dengan Prinsip "Kerajaan Allah" (Y)}

Hasil pengujian hipotesis pertama yang menduga bahwa ada korelasi kuat antara Variabel $\mathrm{X}$ dan $\mathrm{Y}$, ternyata hanya memiliki korelasi yang rendah. Hasil ini menunjukkan bahwa pemahaman dan implementasi prinsip "Mengumpulkan Harta di Surga" (Variabel X) dengan prinsip "Kerajaan Allah" (Variabel Y) di kalangan para hamba Tuhan sinode GSKI masih kurang memadai sehingga perlu ditingkatkan. Hal ini tentunya menyangkut soal sikap dalam mengumpulkan harta benda (Variabel X) yang mempengaruhi sikap terhadap Kerajaan Allah (Variabel Y) yang terbagi ke dalam Variabel Y1, Y2, dan Y3. 
Tuhan Yesus telah memberi peringatan kepada para murid-Nya agar mewaspadai pengaruh negatif dari bahaya mengumpulkan harta atau kekayaan yang bisa menjadi berhala dan mengantikan sikap memprioritaskan pengabdian kepada Allah (Lih. Mat. 6: 24). Hati yang mengabdi kepada Allah dapat digeser oleh harta benda, sebab dimana hartamu berada, disitulah hatimu berada (Mat. 6: 21). Leon Morris memaparkan bahwa pengabdian kepada Kristus dan kepada Kerajaan Allah menuntut kebulatan dan kesungguhan hati. ${ }^{12}$ Senada dengan Morris, John Stott menegaskan bahwa hal penting yang perlu diubah oleh Kristus dalam hati orang percaya adalah sikap terhadap harta dan milik duniawi. ${ }^{13}$ Erastus Sabdono menjelaskan bahwa menjalani kehidupan yang lebih baik sebagai orang Kristen yaitu melakukan apa yang dikehendaki Bapa menyangkut masalah mengelola hati. ${ }^{14}$ Dapat disimpulkan, pembaruan sikap hati menjadi penting dilakukan oleh para hamba Tuhan di sinode GSKI, terutama menyangkut sikap dalam mengumpulkan harta. Para hamba Allah di sinode GSKI perlu mengedepankan sikap hati memprioritaskan pengabdian kepada Allah, kerajaanNya dan kebenaran-Nya, melebihi kekayaan atau kemakmuran finansial. Kerajaan Allah atau Kerajaan Surga harus menjadi prioritas kehidupan dan pelayanan para hamba Tuhan sinode GSKI.

\section{Korelasi Prinsip "Mengumpulkan Harta di Surga (X) Dengan Prinsip "Memprioritaskan Pengbadian Hanya Kepada Allah" (Y1)}

Hasil uji hipotesis kedua yaitu diduga "Ada Korelasi Yang Kuat Antara Mengumpulkan Harta di Surga Dengan Memprioritaskan Pengabdian Hanya Kepada Allah (Y1)", ternyata hasilnya berada dalam relasi yang cukup, tapi belum

\footnotetext{
12 Leon Morris, Teologi perjanjian baru (Gandum Mas, 1996), 146.

13 John Stott, Khotbah Di Bukit (Jakarta: Yayasan Bina Kasih/OMF, 1999), 26.

14 Erastus Sabdono, Anda Ingin Kaya? (Jakarta: Rehobot Literature, 2012), 27.
} 
kuat, sebagaimana yang diduga. Hasil ini menunjukkan bahwa pengabdian para hamba Tuhan di sinode GSKI kepada Allah perlu ditingkatkan. Bisa jadi, motivasi mencari keuntungan finansial masih lebih menjadi daya tarik yang lebih kuat daripada hati yang mengabdi hanya kepada Allah.

Hasil di atas membuktikan kebenaran ajaran Tuhan Yesus yang menegaskan bahwa pengabdian kepada Mamon sangat bertentangan dengan pengabdian kepada Allah. Mamon menjadi saingan Allah (Mat. 6: 24). Kata "Mamon" muncul dalam Alkitab hanya di Matius 6: 24 dan Lukas 16: 9, 11, 13. Kata "Mamon" ( $\mu \alpha \mu \mu \omega v \tilde{\alpha} \varsigma$, baca: mammonas) berasal dari kata bahasa Aram yang berarti "kekayaan atau harta". Mamon berarti "wealth" (kekayaan) atau "property" (kepemilikan) dipersonifikasi dan ditunjuk sebagai seorang tuan yang berpotensi. $^{15}$ Verkuyl menegaskan bahwa sikap mengabdi kepada Allah merupakan respon dari anugerah Allah, berupa pengampunan dosa, pembaharuan hidup, kemenangan atas kejahatan dan maut. ${ }^{16}$ Seorang yang mengabdi kepada Allah perlu terus berjuang agar memiliki karakter sempurna seperti Bapa di sorga adalah sempurna (Mat. 5: 48). Sikap yang benar dalam merespon anugerah Allah yang memelihara dan mencukupkan kebutuhan anak-anak-Nya inilah yang harus lebih dimaknai, direspon positif dan dihidupi oleh para hamba Tuhan di sinode GSKI agar dapat meningkatkan pengabdian-Nya hanya kepada Allah. Jika tidak demikian, pengabdian kepada Allah akan digantikan oleh daya tarik Mamon.

Tuhan Yesus dalam pengajaran-Nya tentang hal mengumpulkan harta menantang para murid-Nya dan orang banyak untuk memilih siapa yang menjadi tuan atas hidup pendengar-Nya: Allah atau Mamon (Mat. 6: 24). Yesus memakai

15 Donald A. Hagner, Word Biblical Commentary (Matthew 1-13) (USA: Library of Congress Catalogig-in-Publication-Data, 1993), 159.

16 J Verkuyl, Khotbah Di Bukit (Jakarta: BPK Gunung Mulia, 2010), 95. 
perumpamaan tentang hamba dan tuannya (pemiliknya). Dengan tegas Yesus menjelaskan bahwa seseorang tidak bisa mengabdi kepada dua tuan, dan adalah suatu hal yang mustahil apabila seseorang mau menyembah Allah sekaligus juga menyembah Mamon. Stott menegaskan bahwa seharusnya memilih salah satunya, Allah atau Mamon. ${ }^{17}$ Mamon dapat menjadi hamba yang baik, namun sekaligus juga dapat menjadi tuan yang jahat. Mamon atau harta kekayaan seharusnya menjadi hamba bagi orang percaya, sehingga orang percaya dapat menjadikan Allah sebagai Tuan dalam kehidupannya, dan bukan Mamon. France memberikan peringatan bahwa sikap angkuh karena memiliki harta benda dan kesetiaan kepada Allah akan saling bersaing dan sering menyebabkan terjadinya konflik antara materialisme dan kerajaan Allah, hal ini merupakan persoalan yang tidak dapat dihindarkan. ${ }^{18}$ Pilihan hanya dua, mengandalkan anugerah Allah atau Mamon dalam menjalani panggilan hidup sebagai hamba Tuhan. Ini menjadi peringatan yang penting bukan hanya kepada para hamba Tuhan tetapi setiap anak-anak Tuhan, terutama menghadapi derasnya arus materialisme di era disrupsi teknologi saat ini.

\section{Korelasi Prinsip "Mengumpulkan Harta di Surga" (X) dengan Prinsip "Memprioritaskan Kerajaan Allah" (Y2).}

Hasil pengujian hipotesis ketiga yaitu "Ada Korelasi Yang Kuat Antara Mengumpulkan Harta di Surga dengan Memprioritaskan Kerajaan Allah (Y2)”, ternyata berada dalam korelasi rendah. Hasil ini menunjukkan bahwa sikap para hamba Tuhan di sinode GSKI dalam memprioritaskan kerajaan Allah masih perlu dioptimalkan. Kondisi ini juga menunjukkan sikap hamba Tuhan di sinode GSKI

18 R. T. France, The Gospel of Matthew (United Kingdom: Wm. B. Eerdmans Publishing, 2007), 
yang masih kuat mengharapkan gaji atau honor yang tinggi. Tanpa disadari hal ini mengeser prioritas pelayanan sehingga lebih mencari keuntungan dengan mengutamakan gaji daripada pelayanan. Tanhidy menjelaskan bahwa hal tersebut bisa terjadi karena para hamba Tuhan kurang menyadari profesinya sebagai hamba Tuhan yang bertujuan memberikan pengabdian pada masyarakat dan bukan semata-mata untuk mencari keuntungan secara materi/finansial bagi diri sendiri. $^{19}$

Prinsip "Memprioritaskan Kerajaan Allah" (Y2) merupakan perintah Tuhan Yesus agar memprioritaskan Kerajaan Allah dan kebenaran-Nya yang terdapat dalam Matius 6: 33. Ini merupakan tema penting dari perikop Matius 6: 25-34 yang merupakan bagian dari Khotbah di Bukit. Kekuatiran sering menghinggapi kehidupan orang banyak, termasuk para hamba Tuhan. Obat mujarab menjawab hal ini adalah memprioritaskan untuk mencari dahulu Kerajaan Allah maka semua kebutuhan pengikut Kristus akan dicukupkan. Kata

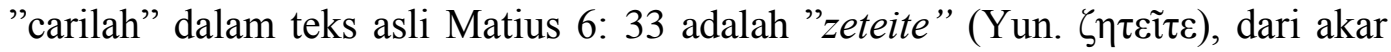

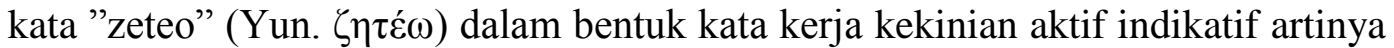
terus-menrus dilakukan sebagai prioritas hidup para murid Kristus $^{20}$ dan menunjuk pada usaha yang sungguh-sungguh dan tekun untuk memperoleh sesuatu, yaitu Kerajaan Allah dan kebenarannya. ${ }^{21}$

Poin penting yang ingin Tuhan Yesus ketengahkan yaitu kuasa Kerajaan Allah (Mat. 6: 33) bukan kepada kekuatiran. Kembali soal Kerajaan Allah. menjadi inti pemberitaan Kristus. Senada dengan ajaran Kristus mengenai

19 Jamin Tanhidy, "Profesionalisme Hamba Tuhan," 2017, 85.

20 Sonta Siketang, "Mencari Kerajaan Allah Dan Kebenarannya Dan Implementasinya Bagi Kehidupan Orang Kristen Masa Kini (Studi Eksegetis Matius 6:33)," Areopagus : Jurnal Pendidikan Dan Teologi Kristen 19, no. 1 (31 Maret 2021): 135-42, https://doi.org/10.46965/ja.v19i1.579.

${ }^{21}$ Stott, Khotbah Di Bukit, 98. 
kerajaan Allah, Margaret Hannan mengemukakan bahwa tema utama perikop ini sebenarnya bukanlah tentang hal kekuatiran, namun kehidupan sejati yang harus dijalani oleh para murid Yesus dan orang percaya. Ia menyimpulkan bahwa tema Kerajaan Allah adalah kerangka utama bangunan Injil Matius. ${ }^{22}$ Mencari kerajaan Allah itulah yang menjadi jaminan pemenuhan kebutuhan hidup para pengikut Kristus, hal ini pula akan menghalau kekuatiran dalam diri para pelayan dan pengikut-Nya yaitu semua kebutuhan hidup akan dicukupkan oleh Allah BapaNya.

Kerajaan Allah menjadi topik bahasan menarik dari para teolog. Morris misalnya, memaparkan konsep Kerajaan Allah dalam Injil Matius yang ia percaya sudah hadir sebab Yesus sudah datang ke dunia. Namun Kerajaan itu juga masih akan datang (bersifat eskatologis). ${ }^{23}$ Artinya, Kerajaan Allah dalam Injil Matius bersifat kekinian (yang terwujud dalam kehadiran Kristus dan didemonstrasikan dalam pelayanan-Nya berupa mujizat-mujizat untuk menjawab dan memenuhi kebutuhan hidup manusia), sekaligus bersifat yang akan datang ketika Kristus kembali memerintah sebagai Raja atas alam semesta ini. Selanjutnya, kerajaan Allah itu menurut Stassen dan Gushee merupakan sikap etis kehidupan orang Kristen yang mengikuti teladan hidup-Nya. ${ }^{24}$ Memprioritaskan kerajaan Allah bersifat rohani, ${ }^{25}$ menurut Matthew Henry harus dengan

22 Margaret Hannan, The Nature and Demands of the Sovereign Rule of God in the Gospel of Matthew (London: T \&T Clarck, 2006), 230.

23 Morris, Teologi perjanjian baru, 176.

24 Glen H. Stassen dan David P Gushee, Etika Kerajaan: Mengikut Yesus Dalam Konteks Masa Kini (Penerbit Momentum, 2013), xvi.

25 Nur Budi Santosa, "KONSEP KERAJAAN ALLAH MENURUT YESUS," Jurnal Antusias 2, no. 3 (May 1, 2013):4,https://www.sttintheos.ac.id/ejournal/index.php/antusias/article/view/53. 
kesungguhan hati mengutamakan perkara batiniah yaitu mencari perkara-perkara Kristus sebagai prioritas hidup. ${ }^{26}$

Dengan demikian pemaknaan kerajaan Allah bersifat utuh, baik menyentuh sisi teologis dan etis serta mencakup kebutuhan hidup manusia. Sesungguhnya tidak ada pemisahan antara "rohani" dan "jasmani" akibat pengaruh sekularisasi, jika kita melakukan segala sesuatunya untuk kepentingan dan kerajaan Tuhan, sebagaimana doa Tuhan Yesus yang diajarkan kepada muridmurid-Nya agar kerajaan Allah hadir di bumi seperti di Surga. Sesungguhnya, kekristenan tidak pernah memisahkan antara hal yang jasmani dan rohani, tidak ada ambigu dalam hal ini, sebab Allah menciptakan manusia itu terdiri dari tubuh, jiwa dan roh, maka semua kebutuhan ketiga elemen ini juga akan dipenuhi-Nya, sebagaimana sabda Tuhan Yesus bahwa "Allah Bapa mengetahui semua kebutuhan anak-anak-Nya, baik itu kebutuhan jasmaniah maupun rohaniah (Mat. 6: 32$)$.

Hamba-hamba Tuhan di sinode GSKI perlu memahami kebenaran ini dan memprioritaskan hal jasmani dan rohani secara proporsional ${ }^{27}$ dengan cara mengedepankan terlebih dahulu kerajaan Allah, dengan setia mengabdi dan rajin melakukan tugas pelayanan, setia memberi persepuluhan dan persembahan sekaligus menjadi teladan bagi jemaat yang dilayani, serta mencukupkan diri dengan semua persembahan jemaat baik berupa gaji atau honor dan tunjangan lainnya yang diatur oleh sinode. Selain itu, para hamba Tuhan di sinode GSKI juga perlu mengajarkan kepada jemaat untuk memprioritaskan kerajaan Allah

26 Matthew Henry, Tafsiran Matthew Henry: Injil Matius 1-14 (Surabaya: Penerbit Momentum, 2014), 281-282.

27 Jamin Tanhidy dkk., "Implementasi Etika Kristen Dalam Keluarga Badan Pengurus Jemaat Gereja Kemah Injil Indonesia Propinsi Jawa Tengah," Evangelikal: Jurnal Teologi Injili dan Pembinaan Warga Jemaat 5, no. 1 (31 Januari 2021): 102, https://doi.org/10.46445/ejti.v5i1.348. 
dengan cara mengandalkan anugerah Allah untuk memberkati usaha atau pekerjaan dan semua kebutuhan hidupnya. Dengan jalan inilah para hamba Allah di sinode GSKI memprioritaskan kerajaan Allah, dan jika jemaat diberkati dan juga ikut memprioritaskan kerajaan Allah, maka para hamba Tuhan juga akan diberkati.

\section{Korelasi Prinsip "Mengumpulkan Harta di Surga" (X) Dengan "Memprioritaskan Kebenaran Kerajaan Allah" (Y3)}

Hasil pengujian hipotesis keempat yaitu diduga ”Ada Korelasi Yang Kuat Antara Mengumpulkan Harta di Surga dengan Memprioritaskan Kebenaran Kerajaan Allah (Y3)" ternyata berada pada korelasi rendah. Hasil ini menunjukkan bahwa pemahaman dan implementasi kebenaran kerajaan Allah di kalangan hamba Tuhan sinode GSKI masih perlu dievaluasi dan ditingkatkan.

Kata "kebenaran" dalam Matius 6: 33 adalah dikaiosunen (Yun.

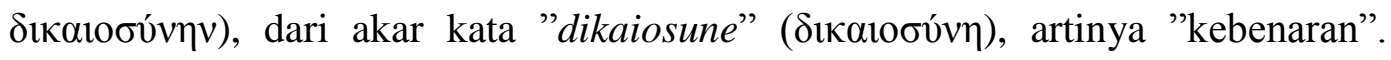
George Eldon Ladd, seorang ahli Perjanjian Baru menjelaskan bahwa salah satu nilai rohani yang dimaksud dalam ayat Matius 6: 33 di atas adalah kata "kebenaran", namun kebenaran yang dimaksud di sini bukanlah kebenaran yang didasarkan pada hukum, melainkan suatu kebenaran yang berdasarkan kepada pembaruan batin yang akan menyanggupkan manusia untuk memenuhi ajaranajaran-Nya. ${ }^{28}$ Pembaruan batin sangat dibutuhkan untuk dapat memahami dan menerapkan kebenaran kerajaan Allah dalam hidup setiap pengikut Kristus. Melengkapi pernyataan Ladd di atas, Wycliffe menjelaskan bahwa perlunya para pengikut Kristus memusatkan perhatian pada nilai-nilai rohani dan bersandar

28 George Eldon Ladd, Teologi Perjanjian Baru 1 (Bandung: Kalam Hidup, 2002), 171. 
penuh kepada Allah ${ }^{29}$ sebagai upaya memaknai dan mengimplementasikan kebenaran kerajaan Allah itu dalam kehidupan sehari-hari.

Pembaruan batin, fokus pada nilai-nilai rohani dan bersandar penuh kepada Allah merupakan sikap hati dan pola hidup yang perlu dimiliki oleh para hamba Tuhan di sinode GSKI untuk dapat mewujudkan kebenaran kerajaan Allah dan mendapatkan manfaat dari kebenaran ajaran Tuhan Yesus ini, baik dalam kehidupan pribadi, keluarga dan pelayanannya.

\section{Prinsip "Memprioritaskan Pengabdian Hanya Kepada Allah" (Y1) Sebagai Variabel Dominan Dengan Prinsip "Mengumpulkan Harta di Surga" (X)}

Berdasarkan hasil pengujian hipotesis kelima yaitu "Variabel yang paling dominan memiliki korelasi dengan prinsip "Mengumpulkan Harta di Surga" (X) adalah variabel "Memprioritaskan Kebenaran Kerajaan Allah" (Y3) ternyata tidak terbukti. Hasil pengujian hipotesis membuktikan bahwa variabel dominan yang memiliki korelasi dengan prinsip "Mengumpulkan Harta di Surga" (X) adalah prinsip "Memprioritaskan Pengabdian Hanya Kepada Allah" (Y1).

Yang menarik untuk dibahas dari hasil pembuktian hipotesis kelima ini yaitu menjawab pertanyaan mengapa prinsip "Memprioritaskan Pengabdian Hanya Kepada Allah" (Y1) menjadi prinsip yang lebih dominan memiliki korelasi dengan prinsip "Mengumpulkan Harta di Surga" (X)? Untuk menjawab pertanyaan di atas, maka harus melihat kembali makna dan fungsi dari prinsip "Memprioritaskan Pengbadian Hanya Kepada Allah". Poin penting dalam prinsip ini ialah "Memprioritaskan Pengabdian Hanya kepada Allah", bukan kepada Mamon. Artinya, dibutuhkan komitmen yang sungguh untuk hanya mengabdi kepada Allah dan kerajaan-Nya, dimana kualitas karakter seorang hamba Tuhan

${ }^{29}$ Charles F. Pfeiffer dan Everett F. Harrison, The Wycliffe Bible Commentary, vol. 3 (Malang: Yayasan Penerbit Gandum Mas, 2001), 42. 
atau pengikut Kristus sangat dibutuhkan di sini. Seorang hamba Allah harus terus berjuang agar memiliki kedewasaan karakter, secara khusus sikap terhadap harta. Rick Warren menulis tentang lima sikap hamba-hamba sejati yang mengabdi dan melayani Allah yaitu: Pertama, lebih banyak memikirkan orang lain daripada diri sendiri, kedua, berpikiran seperti penatalayan, daripada pemilik, ketiga, memikirkan pekerjaan mereka, bukan pekerjaaan orang lain, keempat, melandaskan identitas pribadi di dalam Kristus, kelima, memahami tugas melayani sebagai sebuah kesempatan, hidup, dan bukan sebagai suatu kewajiban. $^{30}$ Visi dan kesadaran memahami panggilan dan identitas sebagai hamba Tuhan harus menjadi motor penggerak kehidupan para hamba Allah yang mengabdikan hidupnya bagi Allah menurut Rick Warren.

Komitmen pengabdian yang tinggi untuk melayani dan mengabdikan seluruh kehidupan hanya kepada Allah sebagai visi kehidupan dan kejayaan kerajaan-Nya harus menjadi agenda utama pelayanan para hamba Tuhan, khususnya hamba Tuhan di sinode GSKI. Sebaliknya para hamba Tuhan harus menghindari sikap mengabdikan diri kepada "kerajaan" pribadi, dimana menurut Smith sering menjadi sasaran pencarian manusia mengapai kesejahteraan hidup atau apa pun bentuk dan namanya. ${ }^{31}$ Setelah menjelaskan uraian tentang intisari atau poin utama dalam prinsip memprioritaskan pengabdian hanya kepada Allah di atas, maka jawaban atas pertanyaan di atas ialah bahwa karakter yang berkualitas (kedewasaan karakter), pemahaman visi dan kesadaran akan identitas panggilan sebagai hamba Tuhan serta komitmen dalam mengabdikan diri kepada Allah dan pekerjaan-Nya, menjadi katalisator utama dalam prinsip

30 Rick Warren, The Purpose driven life: what on earth am I here for?, Imprint Edition (Campus Crusade Asia, 2007), 92-96.

31 James K.A Smith, Mendambakan Kerajaan (Surabaya: Penerbit Momentum, 2021), 49. 
"Memprioritaskan Pengabdian Hanya Kepada Allah" (Y1) yang memiliki korelasi dominan dengan pemahaman prinsip ”Mengumpulkan Harta di Surga” (X).

\section{KESIMPULAN}

Pemahaman dan penerapan prinsip "Mengumupulkan Harta di Surga" di kalangan hamba Tuhan sinode GSKI relatif masih rendah dan perlu dievaluasi dan ditingkatkan. Beberapa poin penting hasil temuan penelitian menjadi sumbangsih bagi upaya meningkatkan pemahaman dan penerapan prinsip di atas yaitu: Pertama, para hamba Tuhan di sinode GSKI perlu mengedepankan sikap hati untuk lebih memahami dan menerapkan prinsip "memprioritaskan pengabdian hanya kepada Allah, kerajaan-Nya dan kebenaran-Nya”, melebihi kekayaan atau kemakmuran finansial. Kedua, mengandalkan anugerah Allah dalam menjalani panggilan hidup sebagai pelayan atau hamba Allah dan selaku pengikut Yesus Kristus, bukan mengandalkan materi atau uang. Ketiga, memprioritaskan kerajaan Allah dengan kesungguhan hati mengutamakan perkara batiniah yaitu mencari perkara-perkara Kristus sebagai prioritas hidup dan pelayanan kepada sesama. Keempat, memprioritaskan kebenaran kerajaan Allah dengan cara memiliki pembaruan batin, fokus pada nilai-nilai rohani dan bersandar penuh kepada Allah serta menghindari ambisi membangun kerajaan pribadi yang sering kali bertentangan dengan kehendak Allah. Kelima, perlu memiliki karakter yang berkualitas (kedewasaan karakter), pemahaman visi dan kesadaran akan identitas panggilan sebagai hamba Tuhan serta komitmen dalam mengabdikan hidup hanya kepada Allah. Dengan demikian ketiga prinsip kerajaan Allah (Varibael Y1,Y2,Y3) yang dipaparkan dalam penelitian ini, harus dilakukan secara simultan 
dan terintegrasi sehingga dapat mempertahankan korelasi yang positif dengan prinsip "Mengumpulkan Harta di Surga" (Variabel X).

\section{DAFTAR PUSTAKA}

France, R. T. The Gospel of Matthew. United Kingdom: Wm. B. Eerdmans Publishing, 2007.

Hagner, Donald A. Word Biblical Commentary (Matthew 1-13). USA: Library of Congress Catalogig-in-Publication-Data, 1993.

Hannan, Margaret. The Nature and Demands of the Sovereign Rule of God in the Gospel of Matthew. London: T \&T Clarck, 2006.

Henry, Matthew. Tafsiran Matthew Henry: Injil Matius 1-14. Surabaya: Penerbit Momentum, 2014.

Herlianto. Teologi Sukses. Jakarta: BPK Gunung Mulia, 2012.

Koan, Cindy Quartyamina, dan Yahya Wijaya. "Teologi sukses dan spiritual capital :: Kajian terhadap teologi sukses Gereja Bethany IndonesiaSurabaya dari perspektif spiritual capital dalam konteks Indonesia." Universitas Gadjah Mada, 2008. http://etd.repository.ugm.ac.id/penelitian/detail/40228.

Ladd, George Eldon. Teologi Perjanjian Baru 1. Bandung: Kalam Hidup, 2002.

Morris, Leon. Teologi perjanjian baru. Gandum Mas, 1996.

Panggara, Robby. "Konsep Kerajaan Allah Menurut Injil-Injil Sinoptik." Jurnal Jaffray, 1, 1 (2013). http://dx.doi.org/10.25278/jj71.v11i1.74.

Pfeiffer, Charles F., dan Everett F. Harrison. The Wycliffe Bible Commentary. Vol. 3. Malang: Yayasan Penerbit Gandum Mas, 2001.

Sabdono, Erastus. Anda Ingin Kaya? Jakarta: Rehobot Literature, 2012.

Datanglah KerajaanMu. Jakarta: Rehobot Literature, 2019.

Santosa, Nur Budi. "KONSEP KERAJAAN ALLAH MENURUT YESUS." Jurnal Antusias 2, no. 3 (1 Mei 2013): 133-44. https://www.sttintheos.ac.id/e-journal/index.php/antusias/article/view/53.

Sasmoko. Metode Penelitian. Jakarta: Media Plus, 2011.

Sasmoko, Sasmoko. Metode Penelitian. Jakarta: UKI Press, 2003. 
Sihaloho, Judika. Wawancara dengan Penulis, 22 November 2019.

Siketang, Sonta. "Mencari Kerajaan Allah Dan Kebenarannya Dan Implementasinya Bagi Kehidupan Orang Kristen Masa Kini (Studi Eksegetis Matius 6:33)." Areopagus: Jurnal Pendidikan Dan Teologi Kristen 19, no. 1 (31 Maret 2021): 135-42. https://doi.org/10.46965/ja.v19i1.579.

Smith, David L. A Handbook of Contemporary Theology: Tracing Trends and Discerning Directions in Today's Theological. Grand Rapids, Michigan: Baker Books, 2000.

Smith, James K.A. Mendambakan Kerajaan. Surabaya: Penerbit Momentum, 2021.

Stassen, Glen H., dan David P Gushee. Etika Kerajaan: Mengikut Yesus Dalam Konteks Masa Kini. Penerbit Momentum, 2013.

Stott, John. Khotbah Di Bukit. Jakarta: Yayasan Bina Kasih/OMF, 1999.

Tanhidy, Jamin. "Profesionalisme Hamba Tuhan," 2017.

Tanhidy, Jamin, Muner Daliman, Hana Suparti, dan Krido Siswanto. "Implementasi Etika Kristen Dalam Keluarga Badan Pengurus Jemaat Gereja Kemah Injil Indonesia Propinsi Jawa Tengah.” Evangelikal: Jurnal Teologi Injili dan Pembinaan Warga Jemaat 5, no. 1 (31 Januari 2021): 102. https://doi.org/10.46445/ejti.v5i1.348.

Verkuyl, J. Khotbah Di Bukit. Jakarta: BPK Gunung Mulia, 2010.

Warren, Rick. The Purpose driven life: what on earth am I here for? Imprint Edition. Campus Crusade Asia, 2007.

Wijaya, Hengki, dan Yoktafianus Harimisa. "Spiritualitas Kerajaan Allah: Khotbah Yesus di Bukit dan Implikasinya bagi Kehidupan Kristen," 20 Desember 2015. https://repository.sttjaffray.ac.id/id/publications/269449/.

Wisantoso, Sandra. "Korelasi Konsep Kerajaan Allah Dan Pemuridan Dalam Injil Matius Bagi Pemuridan Masa Kini." Veritas: Jurnal Teologi Dan Pelayanan 18, no. 1 (15 Oktober 2019): 45-67. https://doi.org/10.36421/veritas.v18i1.323.

Yang, Ferry. "Kerajaan Allah: Sebuah Tinjauan Eksegesis." Jurnal Veritas, 1, 15 (2014): 35-59. http://repository.seabs.ac.id/handle/123456789/296. 